\title{
Gas Permeation through Polymer/Liquid Crystal Composite Membrane
}

\author{
Shintaro WASHIZU, Ichiro TERADA, Tisato KAJIYAma, ${ }^{*}$ \\ and Motowo TAKAYANAGI
}

Department of Applied Chemistry, Faculty of Engineering, Kyushu University 36, Hakozaki, Higashi-ku, Fukuoka 812, Japan

(Received October 28, 1983)

\begin{abstract}
Gas permeation was investigated for a polycarbonate (PC)/ $\mathrm{N}$-(4-ethoxybenzylidene)-4'-butylaniline (EBBA) $\left(=40 / 60\right.$ in $\left.\mathrm{wt}^{\circ} \%\right)$ composite membrane on the basis of its surface and internal structures. Scanning electron microscopic observations for the matrix polymer after extraction of EBBA with hot ethanol showed that EBBA molecules form a continuous phase in the three-dimensional network of PC fibrils. On the basis of sorption and sorption-desorption experiments the composite membrane could be regarded as a homogeneous medium in the range above the crystal-nematic phase transition temperature $T_{\mathrm{KN}}$. The permeability coefficients $P$ for hydrocarbon gases in the composite membrane above $T_{\mathrm{KN}}$ increased discontinuously $100-200$ times as much as those below $T_{\mathrm{KN}}$ over several degrees in the $T_{\mathrm{KN}}$ range. $P$ for hydrocarbon gases below $T_{\mathrm{KN}}$ decreased with an increase in the number of carbon atoms, while those above $T_{\mathrm{KN}}$ showed the opposite trend with an increase in the number of carbon atoms. These facts clearly indicated that permeation is predominantly controlled by diffusion below $T_{\mathrm{KN}}$ and significantly by solubility above $T_{\mathrm{KN}}$.

KEY WORDS Polymer-Liquid Crystal Composite Membrane / Polycarbonate / $N$-(4-Ethoxybenzylidene)-4'-butylaniline / Gas Permeation / Sorption / Diffusion / Laminated Membrane /
\end{abstract}

Fundamental functions of a membrane such as permeability and selectivity, are important in its practical applications. The recent development of new functional polymers has made it possible to produce ultra-thin and also mechanical- and heat-stable membranes with various functions.

Biological membranes are considered good functional models for the molecular design of synthetic membranes. Therefore, it has become important how skillfully to introduce the function principles of biological membranes to synthetic ones. Biological membranes have characteristic functions such as facilitated transport, active transport, dynamic-membrane transport in addition to the capacity for selective separation and filtration. ${ }^{1}$ Also, biological membranes are in a liquid crystal- line state, capable of reversible structural modification, and their gas permeability depends on such reversible changes. ${ }^{2-5}$

Permeation of gases and liquids through polymer films has been studied in relation to chemical nature, aggregation state and thermal molecular motion of matrix polymer chains. ${ }^{6,7}$ The effects of thermal molecular motion on permeation characteristics are of interest, since they reflects the diffusion behavior of permeable molecules. In previous papers, ${ }^{8-11}$ we reported on functional membranes displaying discontinuous jumps in the permeation of water or gas in the temperature range corresponding to the primary relaxation process or the phase transition of the membrane polymer. Polymer/liquid crystal composite membranes in which the liquid crystalline material

\footnotetext{
* To whom correspondence should be addressed.
} 
is embedded in the polymer matrix, are applicable to permeation control, since a distinct change in thermal molecular motion occurs at the crystal-liquid crystal phase transition temperature. Also, the characteristic orientation under an applied electric field and fluidity with a low viscosity ${ }^{12}$ of the liquid crystalline material can be used for the permeation control of permeable molecules.

The present work is primarily concerned with the structural properties and permeation characteristics of composite membranes consisting of polymers and liquid crystalline materials.

\section{EXPERIMENTAL}

\section{Materials}

A polymer/liquid crystal composite membrane was prepared by casting a $6 \mathrm{wt} \% 1,2-$ dichloroethane (DCE) solution of polycarbonate (PC) and $N$-(4-ethoxybenzylidene)- 4'butylaniline (EBBA) on a glass plate at $293 \mathrm{~K}$. The chemical structures of PC and EBBA are shown in Figure 1. The membrane was dried in vacuo at $293 \mathrm{~K}$ for one week. The thickness of the membrane was about $100 \mu \mathrm{m}$.

The PC/EBBA composite membrane contained $60 \mathrm{wt} \%$ EBBA (40/60 composite membrane). PC was used as the matrix substance for the composite membrane, since it exhibits no thermal transition in the temperature range studied here. ${ }^{13}$ By differential scanning calorimetry (DSC), two endothermic peaks for

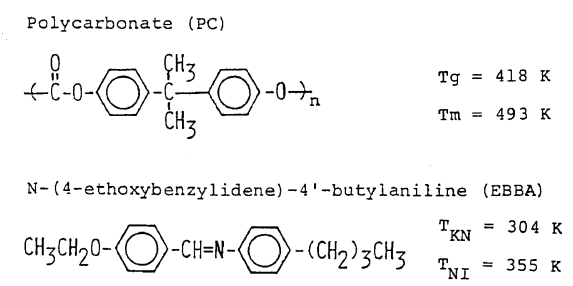

Figure 1. Chemical structures of PC and EBBA. $T_{\mathrm{g}}$ and $T_{\mathrm{m}}$ are the glass transition and melting temperatures of PC, respectively. $T_{\mathrm{KN}}$ and $T_{\mathrm{NI}}$ are the crystal-nematic and nematic-isotropic transition temperatures of EBBA, respectively.
EBBA were observed to correspond to the crystal-nematic $\left(T_{\mathrm{KN}}=304 \mathrm{~K}\right)$ and nematicisotropic $\left(T_{\mathrm{NI}}=355 \mathrm{~K}\right)$ phase transitions, respectively. A laminated membrane was also prepared by sticking a thin PC film $(\sim 8 \mu \mathrm{m})$ to the surface of the $40 / 60$ composite membrane with DCE. ${ }^{14}$ All these membranes were cured at $333 \mathrm{~K}$ (well above $T_{\mathrm{KN}}$ ) for $2 \mathrm{~h}$ under a nitrogen atmosphere.

The gases used were $\mathrm{He}, \mathrm{N}_{2}, \mathrm{CH}_{4}, \mathrm{C}_{3} \mathrm{H}_{8}$, $\mathrm{C}_{4} \mathrm{H}_{10}$, and iso- $\mathrm{C}_{4} \mathrm{H}_{10}$. The hydrocarbon gas purity was greater than $99.5 \%$.

\section{Measurements}

Scanning Electron Microscopy (SEM). The surface and internal states of the membranes were observed for a sample coated with gold, using a Hitachi Scanning Electron Microscope S-430.

Infrared Spectroscopy (IR). Infrared spectra were obtained by the transmission and attenuated total reflection (ATR) methods, using a Perkin-Elmer 567 Grating Infrared Spectrometer. For the ATR method, the depth of IR beam penetration, $d_{\mathrm{p}}$, was calculated by ${ }^{15}$

$$
\begin{gathered}
d_{\mathrm{p}}=\frac{\lambda}{2 \pi n_{1}\left(\sin ^{2} \theta-n_{21}^{2}\right)^{1 / 2}} \\
n_{21}=n_{2} / n_{1},
\end{gathered}
$$

where $n_{1}, n_{2}, \theta$, and $\lambda$ are the refractive indices of the reflection plate $\left(2.37\right.$ for KRS- $\left.5^{16}\right)$ and the sample ( 1.45 for the PC/EBBA composite membrane), the effective incident angle $\left(45^{\circ}\right)$ and the wavelength of a characteristic absorption band, respectively. $n_{2}$ was evaluated, assuming the additivity of the refractive indices of $\mathrm{PC}^{17}$ and EBBA. ${ }^{18}$

Sorption and Desorption Measurements. Sorption and desorption measurements on hydrocarbon gases were carried out using a Cahn 2000 electrobalance at two temperatures below and above $T_{\mathrm{KN}}$.

Gas Permeation Measurement. Permeation of $\mathrm{He}, \mathrm{N}_{2}$, and hydrocarbon gases through the composite membrane was investigated by the 
high vacuum method ${ }^{19}$ in the temperature range from 283 to $333 \mathrm{~K}$. The pressure on the upstream side ranged from 40 to $45 \mathrm{cmHg}$. An increase in pressure on the downstream side was measured with a McLeod gage as a function of time. The diffusion coefficient of a given gas was evaluated by the time-lag method. ${ }^{20}$

\section{RESULTS AND DISCUSSION}

\section{Aggregation States of $P C$ and EBBA in the} Composite Membrane

Our composite membrane was prepared from a DCE solution of PC and EBBA. Hence, it was important to investigate the aggregation state of EBBA molecules in the membrane by DSC, X-ray, density, and dynamic mechanical measurements. Our previous study ${ }^{13}$ showed that EBBA molecules in the composite membrane were nearly molecularly dispersed up to $30 \mathrm{wt} \%$ EBBA, and above this, they formed domains in the PC polymer matrix. This indicates that the compatibility of the two components was fairly good and no particularly strong repulsion acted between them.

Figure 2 shows the SEM photograph for a 40/60 composite membrane from which EBBA molecules were almost completely extracted with hot ethanol $\left(333 \mathrm{~K},>T_{\mathrm{KN}}\right)$. The $\mathrm{PC}$ matrix forms a three-dimensional fibrillar network and the EBBA molecules interpenetrate into a continuous phase in the threedimensional PC network. Mechanical toughness of the thin composite film arises from the mutual interpenetration of PC fibrils and EBBA molecules, and this aggregation structure enables the EBBA molecules to exist stably in the composite membrane.

Next, we investigated the aggregation state of the components in the composite membrane in terms of the sorption characteristics of gases, such as sorption isotherms and sorption and desorption rates. Figure 3 shows the sorption isotherms of $\mathrm{CH}_{4}, \mathrm{C}_{3} \mathrm{H}_{8}$, and $\mathrm{C}_{4} \mathrm{H}_{10}$ for the $40 / 60$ composite membrane. The measurements were carried out at

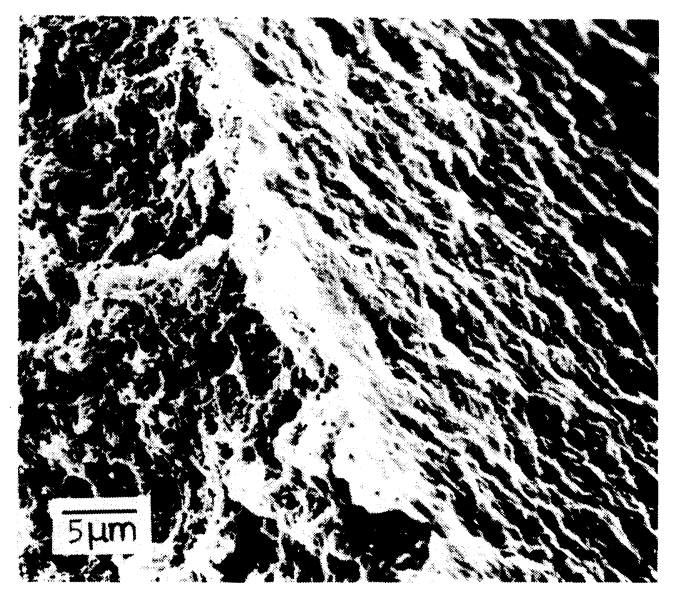

Figure 2. Scanning electron micrograph of 40/60 composite membrane after the complete extraction of EBBA with ethanol.

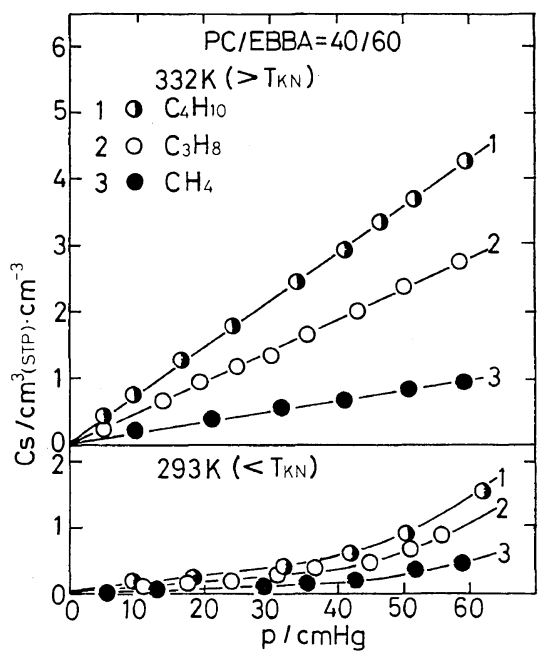

Figure 3. Sorption isotherms for $\mathrm{C}_{4} \mathrm{H}_{10}, \mathrm{C}_{3} \mathrm{H}_{8}$, and $\mathrm{CH}_{4}$ in $40 / 60$ composite membrane at $293\left(<T_{\mathrm{KN}}\right)$ and $332 \mathrm{~K}\left(>T_{\mathrm{KN}}\right)$.

two temperatures below $(293 \mathrm{~K})$ and above (332 K) $T_{\mathrm{KN}}$. The sorption isotherms below $T_{\mathrm{KN}}$ were similar to the Freundrich-type, while those above $T_{\mathrm{KN}}$ obeyed Henry's law. The slope of a sorption isotherm gives the value of a solubility coefficient; the calculated values of the coefficient for $\mathrm{CH}_{4}, \mathrm{C}_{3} \mathrm{H}_{8}$, and $\mathrm{C}_{4} \mathrm{H}_{10}$ at $332 \mathrm{~K}\left(>T_{\mathrm{KN}}\right)$ were $1.69 \times 10^{-2}$, $4.42 \times 10^{-2}$, and $7.50 \times 10^{-2} \mathrm{~cm}^{3} \quad(\mathrm{STP}) /$ 


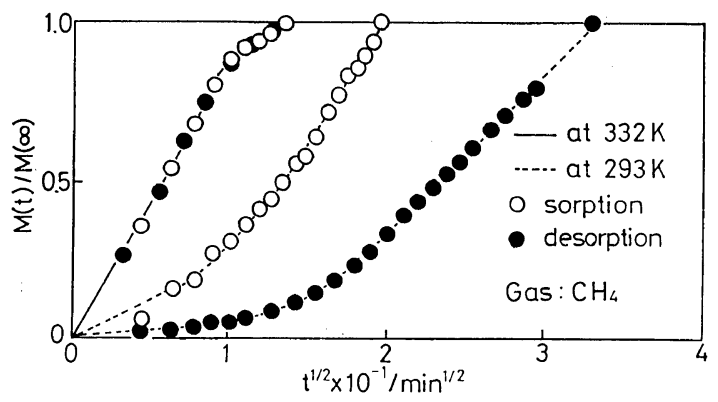

Figure 4. Sorption-desorption curves for $\mathrm{CH}_{4}$ in the $40 / 60$ composite membrane at $293\left(<T_{\mathrm{KN}}\right)$ and $322 \mathrm{~K}\left(>T_{\mathrm{KN}}\right)$.

$\mathrm{cm}^{3} \mathrm{cmHg}$, respectively. Therefore, the solubility coefficient for $\mathrm{C}_{4} \mathrm{H}_{10}$ was about 1.7 and 4.4 times those for $\mathrm{C}_{3} \mathrm{H}_{8}$ and $\mathrm{CH}_{4}$, respectively. If the sorbed amount of gas is plotted against activity, the difference in the sorption isotherms for these gases can be made more apparent.

Figure 4 shows the sorption-desorption curves for $\mathrm{CH}_{4}$ in the $40 / 60$ composite membrane. $M(t)$ is the total amount of penetrant absorbed or left in the membrane at time, $t$, and $M(\infty)$ is the corresponding quantity at infinite time. The sorption and desorption curves at $293 \mathrm{~K}\left(<T_{\mathrm{KN}}\right)$ were somewhat complex non-Fickian, indicating that the diffusion coefficient $D$ depended not only on the penetrant concentration but also on time. The time dependence of $D$ is strongly related to the relaxation behavior of the membrane components. On the other hand, a linear relation was found between $M(t) / M(\infty)$ and $t^{1 / 2}$ at the early stage of sorption at $332 \mathrm{~K}\left(>T_{\mathrm{KN}}\right)$. This sorption behavior suggests that the system is Fickian above $T_{\mathrm{KN}}$. Also, the sorption and desorption curves coincided throughout the entire range of measuring time. Similar sorption-desorption data were obtained for $\mathrm{C}_{3} \mathrm{H}_{8}$ and $\mathrm{C}_{4} \mathrm{H}_{10}$ at corresponding temperatures. From these, equilibrium was established immediately and $D$ of each hydrocarbon gas was independent of penetrant concentration, ${ }^{21}$ in the range above the phase transition temperature of EBBA. It is well known that sorption isotherms obeying Henry's law and Fickian sorptions are observed for systems of organic vapor and amorphous polymer in the rubbery state. ${ }^{22,23}$ Consequently, our sorption isotherms and sorption-desorption curves indicate that the $40 / 60$ composite membrane above $T_{\mathbf{K N}}$ can be regarded as a homogeneous medium as far as gas permeation is concerned.

\section{Surface States of the 40/60 Composite and Laminated Membranes}

Figures 5(a) and (b) show the SEM photographs of the fracture (the upper portion) and surface (the lower portion) of the $40 / 60 \mathrm{com}$ posite and laminated membranes; both were quenched with liquid nitrogen after annealing at $333 \mathrm{~K}\left(>T_{\mathrm{KN}}\right)$. It is clear from Figure 5(a) that a large number of EBBA domains protrude from the membrane surface like a tongue. This suggests that EBBA domains reversibly stick out and draw back to the membrane surface below and above $T_{\mathrm{KN}}$, respectively, since the volume expansion coefficient of EBBA is larger than that of PC. The surface of the laminated membrane (Figure 5(b)) is very smooth, because EBBA cannot ooze through the PC thin film attached to the 40/60 composite membrane. The PC thin film was about $2-3 \mu \mathrm{m}$ thick, while the PC thin film before lamination was about $8 \mu \mathrm{m}$ thick. This difference suggests that both membranes considerably interpenetrated at their interface. The difference in surface state shown in 

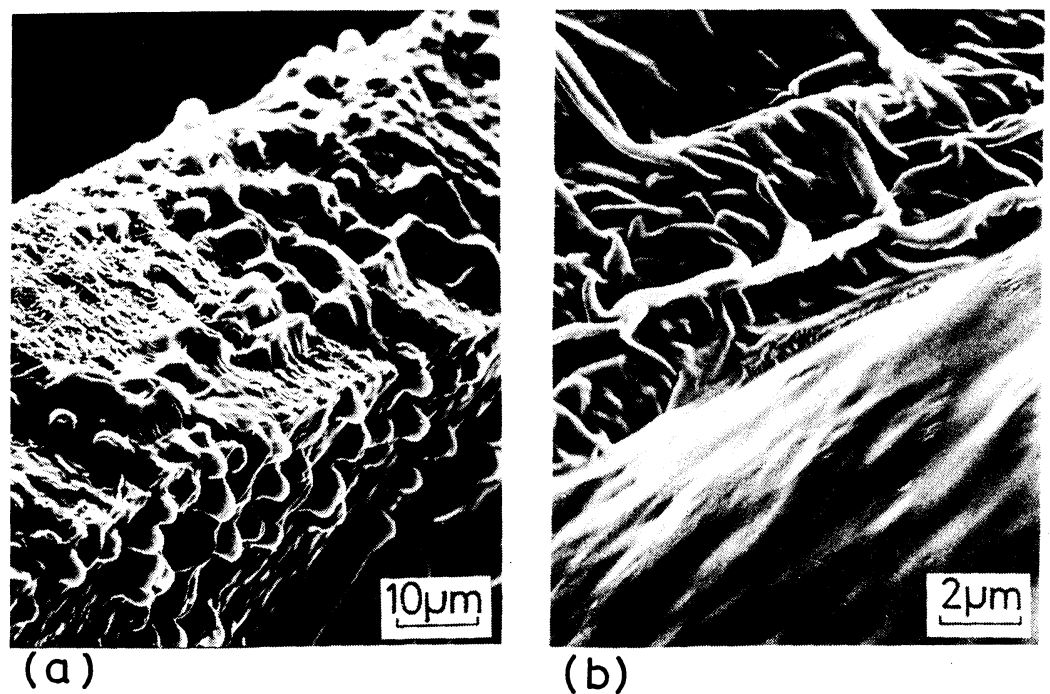

(b)

Figure 5. Scanning electron micrographs of the 40/60 composite (a) and laminated (b) membranes. These were quenched with liq. $\mathrm{N}_{2}$ after annealing at $333 \mathrm{~K}$.

Figures 5(a) and (b) should have great influence upon gas permeation behavior to be described later.

The chemical composition in the surface thin layer of each membrane was determined by IR spectroscopic analysis. IR absorption bands due to the plane deformation of aromatic hydrocarbons in $\mathrm{PC}^{24}$ (curve 1 in Figure 6) and $\mathrm{EBBA}^{25}$ (curve 2) were observed at 1005 and $1040 \mathrm{~cm}^{-1}$ and designated as "a" and " $b$ " in Figure 6, respectively. Curve 3 in this figure shows the IR spectrum for the 40/60 composite membrane. IR data down to a depth of $1.8 \mu \mathrm{m}$ from the surface (calculated from eq 1) were obtained by the ATR-IR method. The weight fraction of EBBA in the surface region down to $1.8 \mu \mathrm{m}$ was evaluated using Sibilia's method. ${ }^{26}$ The weight ratio of PC to EBBA, $W_{\text {PC }} / W_{\text {EBBA }}$, was calculated from

$$
\frac{W_{\mathrm{PC}}}{W_{\mathrm{EBBA}}}=\left(\frac{I_{\mathrm{PC}}}{I_{\mathrm{EBBA}}}\right)\left(\frac{I_{\mathrm{EBBA}}^{0}}{I_{\mathrm{PC}}^{0}}\right)
$$

where $I_{\mathrm{PC}} / I_{\mathrm{EBBA}}$ and $I_{\mathrm{PC}}^{0} / I_{\mathrm{EBBA}}^{0}$ are the ratios of the IR absorbance of the PC band (a) to that of EBBA (b) for the $40 / 60$ and the $50 / 50$ composite membranes, respectively. Thus, the

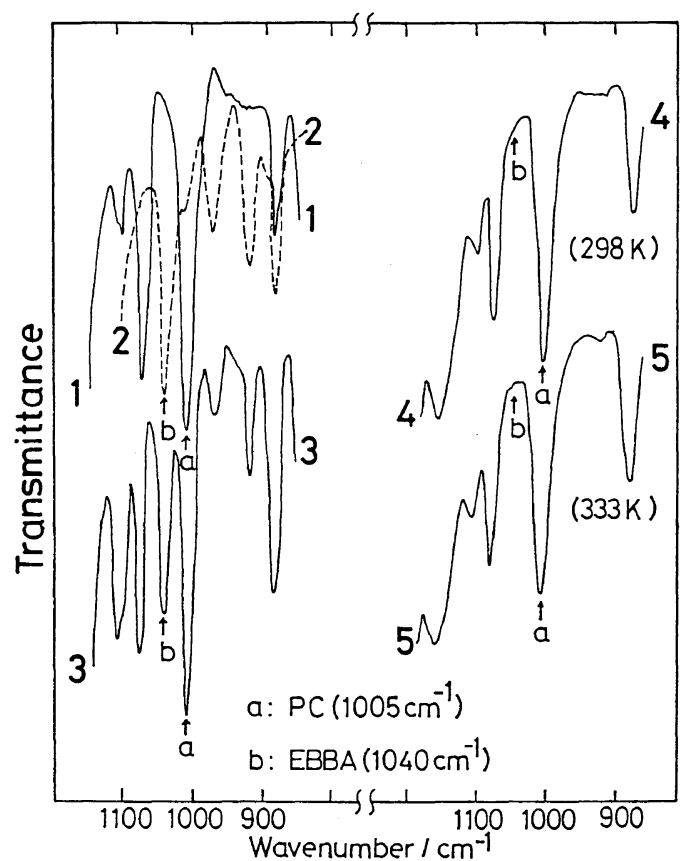

Figure 6. IR spectra for the PC (1), EBBA (2), 40/60 composite membranes (3), and those laminated (4 and 5).

weight ratio was normalized in terms of $I_{\mathrm{PC}}^{0} /$ $I_{\mathrm{EBBA}}^{0}$. Since $W_{\mathrm{PC}}+W_{\mathrm{EBBA}}=100$, the weight $\%$ of EBBA was calculated by 


$$
W_{\mathrm{EBBA}}=\frac{100}{1+\left(I_{\mathrm{PC}} / I_{\mathrm{EBBA}}\right)\left(I_{\mathrm{EBBA}}^{0} / I_{\mathrm{PC}}^{0}\right)}
$$

When eq 4 was used, $W_{\text {EBBA }}$ of the $40 / 60$ composite membrane was $65-70 \mathrm{wt} \%$. This value indicates that the weight fraction of EBBA in the surface region is somewhat greater than the original bulk composition, and fairly close to that from the SEM observation mentioned above. Curves 4 and 5 in Figure 6 are the ATR-IR spectra of the laminated membrane below $(291 \mathrm{~K})$ and above $(333 \mathrm{~K})$ $T_{\mathrm{KN}}$, respectively. These curves show clearly that the chemical composition of the membrane surface on the PC-laminated side does not change even above $T_{\mathrm{KN}}$.

\section{Gas Permeation through the 40/60 Composite Membrane}

Figure 7 shows the Arrhenius plots of the permeability coefficient $P$ for $\mathrm{He}, \mathrm{N}_{2}$ and hydrocarbon gases in the $40 / 60$ composite membrane. A distinct jump in $P$ was observed in the vicinity of $T_{\mathrm{KN}}$. In particular, $P$ for hydrocarbon gases increased approximately 100-200 times within a few degrees in the phase transition region, as shown by the broken lines in Figure 7. In this region, the permeabilities of $\mathrm{He}$ and $\mathrm{N}_{2}$ also increased remarkably, being possible as a result of the activation of thermal molecular motion in the membrane and/or an enhancement of pore formation. The probability of pore formation increases owing to a dynamic phase equilibrium within the EBBA domain in going from the crystalline to the liquid crystalline state. The dynamic phase equilibrium means the coexistence of solid and liquid crystalline phases during the phase transition.

The changes in $P$ for hydrocarbon gases across the phase transition range was nearly reversible. $P$ decreased with an increase in the number of carbon atoms or the occupied volume of gas below the phase transition temperature. This trend suggests that the permeability is predominantly governed by dif-

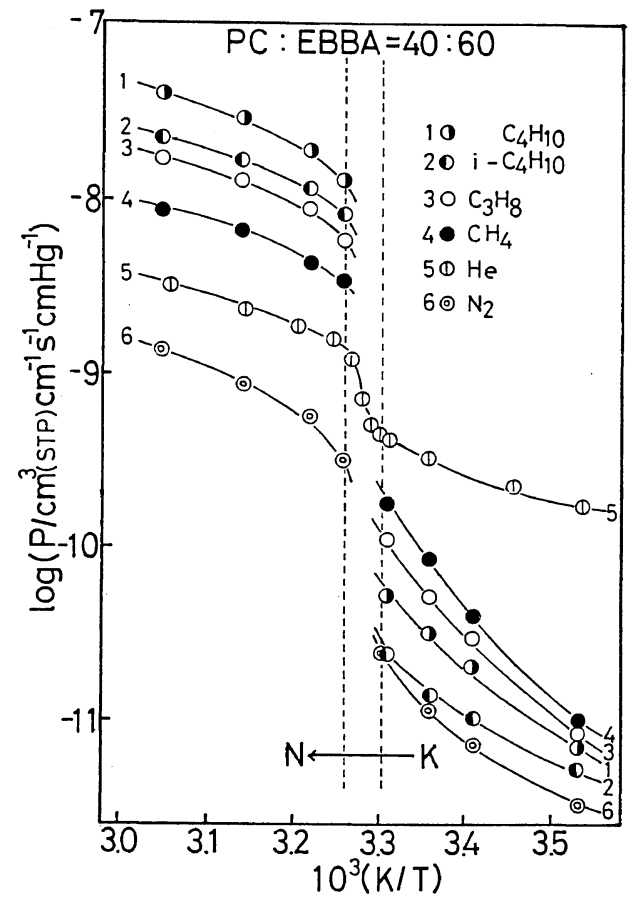

Figure 7. Arrhenius plots of permeability coefficient $P$ for $\mathrm{He}, \mathrm{N}_{2}$, and hydrocarbon gases in the $40 / 60 \mathrm{com}-$ posite membrane.

fusion. On the other hand, above the phase transition temperature, $P$ increased with an increase in the number of carbon atoms. This tendency cannot be explained only by simply diffusion, but indicates that permeation is mainly governed by solubility.

As mentioned previously, the $40 / 60$ composite membrane can be treated as a homogeneous medium above $T_{\mathrm{KN}}$. Hence, the permeability coefficient data should be analyzed separately in terms of diffusion $(D)$ and solubility $(S)$ coefficients, respectively, using the relation,

$$
P=D S
$$

Figure 8 presents the Arrhenius plots of $D$ for $\mathrm{CH}_{4}, \mathrm{C}_{3} \mathrm{H}_{8}, \mathrm{C}_{4} \mathrm{H}_{10}$, and iso- $\mathrm{C}_{4} \mathrm{H}_{10}$ in the $40 / 60$ composite membrane. Though $D$ is independent of penetrant concentration only above $T_{\mathrm{KN}}$ as mentioned previously, $D$ was evaluated by the time-lag method. The diffusion coef- 


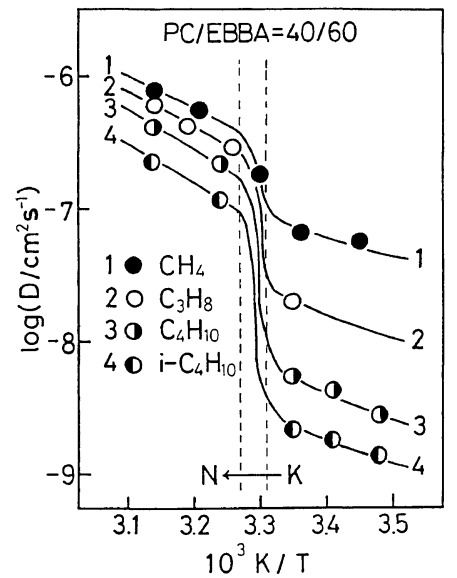

Figure 8. Arrhenius plots of diffusion coefficient $D$ for hydrocarbon gases in the $40 / 60$ composite membrane.

ficients for smaller hydrocarbon gases were greater throughout the entire temperature range studied. $D$ for $\mathrm{CH}_{4}, \mathrm{C}_{3} \mathrm{H}_{8}, \mathrm{C}_{4} \mathrm{H}_{10}$, and iso- $\mathrm{C}_{4} \mathrm{H}_{10}$ above $T_{\mathrm{KN}}$ were $3,8,17$, and 22 larger than those below $T_{\mathrm{KN}}$, respectively. The larger increase in $D$ for $\mathrm{C}_{4} \mathrm{H}_{10}$ and iso- $\mathrm{C}_{4} \mathrm{H}_{10}$ than those for $\mathrm{CH}_{4}$ or $\mathrm{C}_{3} \mathrm{H}_{8}$ indicates a greater effect on $D$ caused by an increase in free volume dimension as well as in free volume fraction in the crystal-nematic phase transition range of EBBA.

Figure 9 shows the Arrhenius plots of $S$ for $\mathrm{CH}_{4}, \mathrm{C}_{3} \mathrm{H}_{8}, \mathrm{C}_{4} \mathrm{H}_{10}$, and iso- $\mathrm{C}_{4} \mathrm{H}_{10}$ in the $40 / 60$ composite membrane. Here, $S$ was evaluated from the data of Figures 7 and 8 by eq $5 . S$ increased with increasing temperature up to the neighborhood of the phase transition temperature, and decreased gradually after passing through a maximum. The negative and positive slopes of the Arrhenius plots for $S$ correspond to positive and negative heats of solution, respectively. This behavior toward $\log S$ vs. 1/T plots indicates that $S$ for penetrant gases in the polymer/liquid crystal composite membrane changes when crossing the phase transition range. The solubility must vary differently with the fractions of $\mathrm{PC}$ and EBBA. The values of $S$ increased in the order of $\mathrm{CH}_{4}, \mathrm{C}_{3} \mathrm{H}_{8}$, iso- $\mathrm{C}_{4} \mathrm{H}_{10}$, and $\mathrm{C}_{4} \mathrm{H}_{10}$ in the

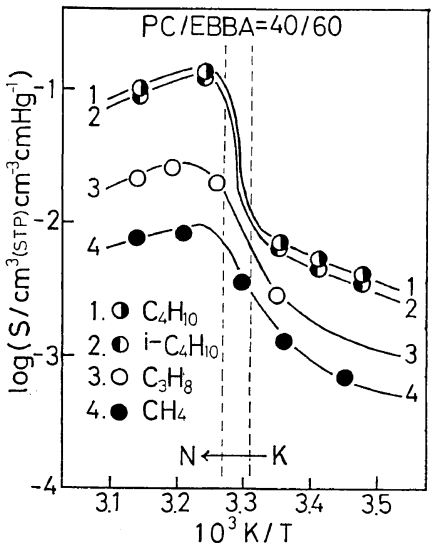

Figure 9. Arrhenius plots of solubility coefficient $S$ for hydrocarbon gases in the $40 / 60$ composite membrane.

entire temperature range studied. It should be noted that the difference in $S$ among hydrocarbon gases were somewhat larger above $T_{\mathrm{KN}}$ than below $T_{\mathrm{KN}}$. However, the corresponding differences in $D$ were smaller above $T_{\mathrm{KN}}$ than below $T_{\mathrm{KN}}$, as seen in Figure 8 . Therefore, Figures 7, 8, and 9 indicate that permselectivity above the phase transition temperature is mainly controlled by solubility, instead of diffusion. It should be worthwhile to investigate the surface state-permeation relationship in the composite membrane in relation to the control of sorption process.

\section{Investigation of Gas Permeation Characteristics with Laminated Membrane}

The gas permeation characteristics of the 40/60 composite membrane was made clearer by studying a laminated membrane. Figure 10 shows two permeation models for laminated membranes having different surface conditions. The permeability coefficient $P_{I}^{*}$ (Model I) is for the permeation from the PC side (sorption to $\mathrm{PC}$ and desorption from the 40/60 composite membrane) and $P_{\text {II }}^{*}$ (Model II) is for that from the composite membrane side (sorption to the $40 / 60$ composite membrane and desorption from PC). The overall permeability coefficient $P^{*}$ was estimated from eq 6 corresponding to a series $\operatorname{model}^{27}$; i.e., 


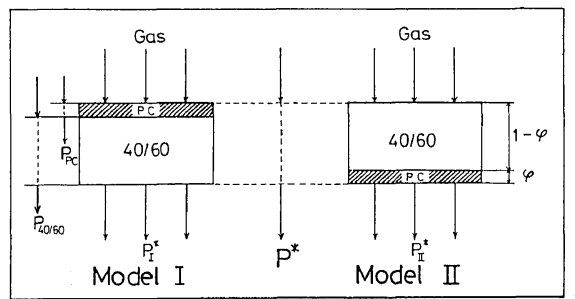

Figure 10. Gas permeation models of laminated membrane. $P_{\mathrm{I}}^{*}$ and $P_{\mathrm{n}}^{*}$ are permeability coefficients for Model I and Model II, respectively. $\varphi$ is the volume fraction of PC.

$$
\frac{1}{P^{*}}=\frac{\varphi}{P_{\mathrm{PC}}}+\frac{1-\varphi}{P_{40 / 60}}
$$

where $P_{\mathrm{PC}}$ and $P_{40 / 60}$ are the permeability coefficients for the PC and 40/60 composite membranes, respectively, and $\varphi$, the volume fraction of $\mathrm{PC}$ in the laminated membrane. Equation 6 is applicable to the permeation through a laminated membrane in which $D$ is independent of the penetrant concentration and $S$ is proportional to the gas pressure. In this study, the $40 / 60$ composite membrane above $T_{\mathrm{KN}}$ appeared to satisfy these requirements, judging from the results in Figures 3 and 4, while the PC membrane in the glassy state had a concentration-dependent $D .{ }^{28}$ Therefore, the experimental values of $P_{\mathrm{I}}^{*}$ and $P_{\text {II }}^{*}$ were expected to differ from $P^{*}$. In such a case, there should exist a difference in solubility between the surfaces of the PC and 40/60 composite membranes.

Figure 11 displays the Arrhenius plots of $P_{\mathrm{PC}}, P_{40 / 60}, P^{*}, P_{\mathrm{I}}^{*}$, and $P_{\mathrm{II}}^{*}$ for $\mathrm{C}_{4} \mathrm{H}_{10}$. The values of $P^{*}, P_{\mathrm{I}}^{*}$, and $P_{\mathrm{II}}^{*}$ are in order of $P_{\mathrm{I}}^{*}<P^{*}<P_{\mathrm{Il}}^{*}$. For Model I, virtually no change in solubility occurs at the membrane surface over the entire temperature range, since PC is situated on the upstream side of the surface. Therefore, the increment in $P_{I}^{*}$ above the phase transition region is due mainly to an increase in diffusivity through the composite membrane. For Model II, solubility effect of $\mathrm{C}_{4} \mathrm{H}_{10}$ on EBBA appears more remarkably than for the generalized series

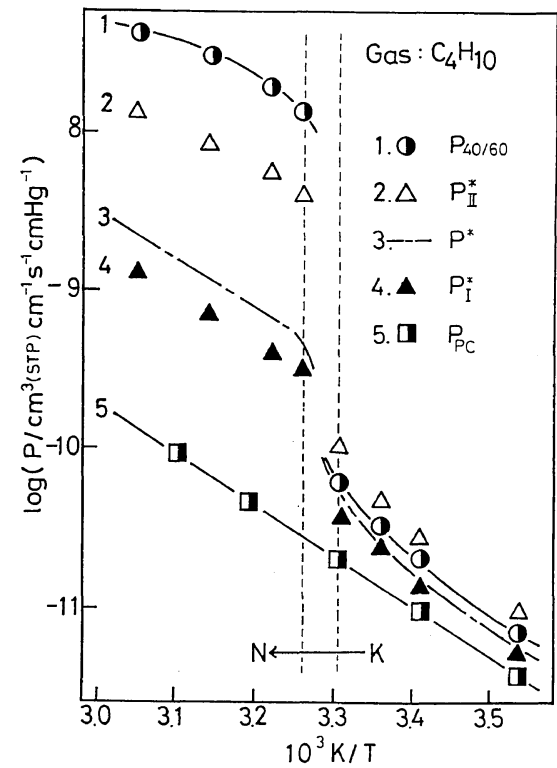

Figure 11. Arrhenius plots of permeability coefficient $P$ for $\mathrm{C}_{4} \mathrm{H}_{10}$ in various composite membranes.

model, especially above $T_{\mathrm{KN}}$, since the sorption surface is the $40 / 60$ composite membrane. These contributions from diffusion and solubility result in the relationship $P_{1}^{*}<P^{*}<P_{\mathrm{II}}^{*}$. Trends similar to $\mathrm{C}_{4} \mathrm{H}_{10}$ permeation were obtained for other hydrocarbon gases.

Figure 12 shows the Arrhenius plots of the permeability coefficient ratio $P_{40 / 60} / P_{1}^{*}$ for hydrocarbon gases. $P_{40 / 60} / P_{1}^{*}$ reflects the differences in the sorption processes of hydrocarbon gases through the $40 / 60$ composite and laminated membranes. Greater differences in $P_{40 / 60} / P_{I}^{*}$ among hydrocarbon gases can be observed in the temperature range above $T_{\mathrm{KN}}$ instead of the range below $T_{\mathrm{KN}}$. The values of $P_{40 / 60} / P_{\mathrm{I}}^{*}$ increased in order of $\mathrm{CH}_{4}, \mathrm{C}_{3} \mathrm{H}_{8}$, iso- $\mathrm{C}_{4} \mathrm{H}_{10}$, and $\mathrm{C}_{4} \mathrm{H}_{10}$ throughout the entire temperature range studied. Since the difference in gas permeability between Model I and the $40 / 60$ composite membrane is caused only by gas solubilities in the membranes, Figure 12 indicates that the gas solubility in EBBA increases with increasing hydrocarbon length. The effects of diffusion on gas permeation within the membrane should also be taken 


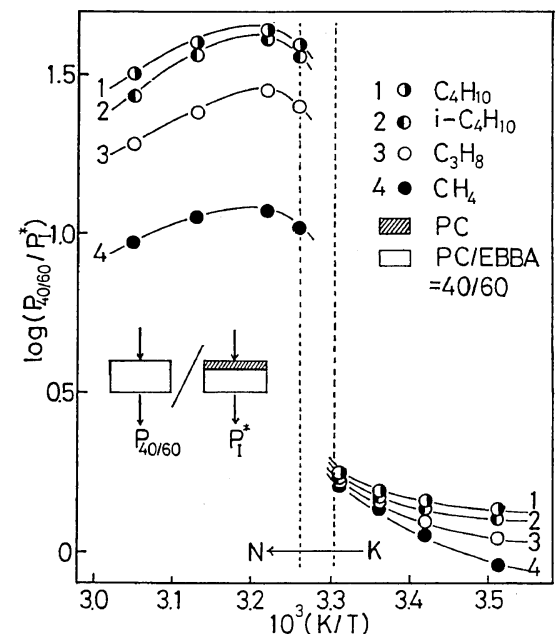

Figure 12. Arrhenius plots of $P_{40 / 60} / P_{1}^{*}$ for hydrocarbon gases.

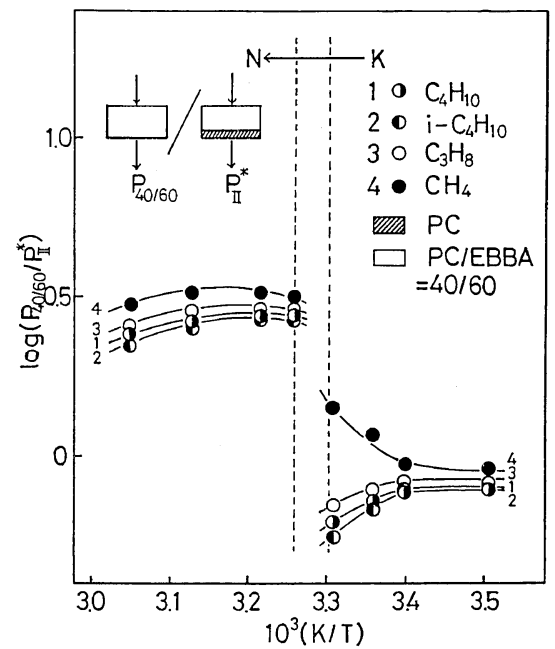

Figure 13. Arrhenius plots of $P_{40 / 60} / P_{\mathrm{II}}^{*}$ for hydrocarbon gases.

into account. Since a shorter alkyl chain gives a larger increase in $D$, as shown in Figure 8 , it is reasonable to consider that $D$ affects more effectively the solubility of hydrocarbon gases.

The Arrhenius plots of $P_{40 / 60} / P_{\text {II }}^{*}$ for hydrocarbon gases in Figure 13 illustrate the influence of desorption on gas permeation. Though the differences in $P_{40 / 60} / P_{\mathrm{II}}^{*}$ among different hydrocarbon gases are not as great as those of $P_{40 / 60} / P_{I}^{*}$ shown in Figure 12, $P_{40 / 60} /$ $P_{\text {II }}^{*}$ decreases with an increase in the length of hydrocarbon. This trend is the opposite of that of $P_{40 / 60} / P_{\mathrm{I}}^{*}$. Since $P_{40 / 60} / P_{\mathrm{II}}^{*}$ reflects the difference in desorption between the composite and laminated membranes, it is reasonable to consider that this quantity increases with the extent to which the gas can be desorbed from the membrane.

From Figures 12 and 13, it is reasonable to consider that the gas permeation characteristics of the $40 / 60$ composite membrane is mainly controlled by solubility rather than by diffusivity, especially above $T_{\mathrm{KN}}$. This may be closely related to the EBBA-rich surface of the composite membrane above $T_{\mathrm{KN}}$ shown in Figure 5(a) and the chemical affinities of hydrocarbon gases toward EBBA.

\section{Membrane Design for Functional Permselec- tivity}

On the basis of the gas permeation properties of the $40 / 60$ composite membrane, the membrane design for functional permselectivity is discussed in the following.

Figure 14 shows the Arrhenius plots of $P_{\mathrm{C}_{4} \mathrm{H}_{10}} / P_{\mathrm{CH}_{4}}$ and $P_{\mathrm{C}_{3} \mathrm{H}_{8}} / P_{\mathrm{CH}_{4}}$ for the PC, $40 / 60$ composite and laminated (Model I and Model II) membranes. It should be noted that the separation power of the laminated membrane for Model II (curve 1 in Figure 14) is greater than those of the $40 / 60$ composite membrane (curve 2), the laminated membrane for Model I (curve 3) and the PC membrane (curve 4). In particular, from a comparison of curves 1 and 2 in this figure, we see that the laminated membrane for Model II has a unique effect on the sorption-desorption processes, for instance, an excellent solubility for $\mathrm{C}_{4} \mathrm{H}_{10}$, which is as good as that of the $40 / 60$ composite membrane, and excellent desolubility comparable to that of PC.

In order to prepare a permselective membrane, sorption, diffusion and desorption must be controlled ideally. From this standpoint, Model II appears to be most effective as a 


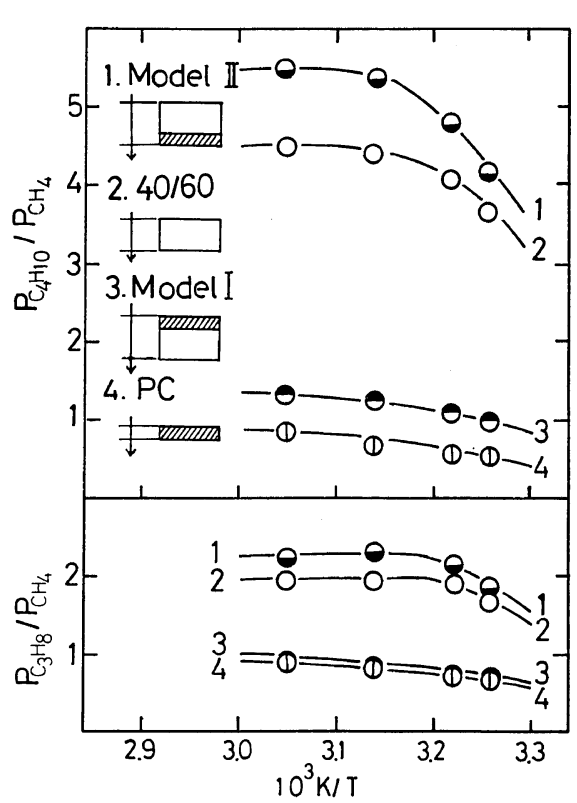

Figure 14. Separation factors, $P_{\mathrm{C}_{4} \mathrm{H}_{10}} / P_{\mathrm{CH}_{4}}$ and $P_{\mathrm{C}_{3} \mathrm{H}_{8}} /$ $P_{\mathrm{CH}_{4}}$, against $1 / T$ for various permeation models.

functional permselective membrane. For preparing a functional permselective membrane consisting of a polymer and a liquid crystalline material, the following subjects should also be investigated:

(1) Combination of the polymer matrix and liquid crystalline material.

(2) Design of an asymmetric composite membrane with a concentration gradient of liquid crystalline material from the upstream to downstream side.

(3) Introduction of an accelerating or facilitating transport function using a carrier substance.

Acknowledgement. This work was partially supported by the Kurata Foundation.

\section{REFERENCES}

1. L. I. Rothfield, "Structure and Function of
Biological Membranes," Academic Press, New York, 1971.

2. C. Tanford, "The Hydrophobic Effect: Formation of Micells and Biological Membranes," John Wiley and Sons, New York, 1973.

3. D. Chapman, R. M. Williams, and B. D. Ladbrooke, Chem. Phys. Lipids, 1, 445 (1976).

4. M. C. Block, L. L. M. van Deenen, and J. De Gier, Biochim. Biophys. Acta, 1, 443 (1976).

5. R. Fettiplace and D. A. Hydon, Physiol. Rev., 60, 510 (1980).

6. A. Takizawa, H. Hamada, H. Okada, S. Imai, and S. Kadota, Polymer, 15, 157 (1974).

7. V. A. Tochin, R. A. Shlyakhov, and D. N. Sapozhnikov, Polym. Sci. U.S.S.R., 17, 2548 (1976).

8. E. Maemura, Y. Nagata, T. Kajiyama, and M. Takayanagi, Rep. Prog. Polym. Phys. Jpn., 20, 663 (1977).

9. Y. Nagata, T. Kajiyama, and M. Takayanagi, Rep. Prog. Polym. Phys. Jpn., 22, 257 (1979); ibid., 23, 663 (1980).

10. T. Kajiyama, Y. Nagata, E. Maemura, and M. Takayanagi, Chem. Lett., 679 (1979).

11. T. Kajiyama, Membrane, 4, 229 (1979); ibid., 6, 265 (1980).

12. G. W. Gray and P. A. Winsor, "Liquid Crystals and Plastic Crystals," John Wiley and Sons, London, 1974.

13. T. Kajiyama, Y. Nagata, S. Washizu, and $\mathbf{M}$. Takayanagi, J. Membrane Sci., 11, 39 (1982).

14. S. Washizu, T. Kajiyama, and M. Takayanagi, Rep. Prog. Polym. Phys. Jpn., 25, 299 (1982).

15. K. Holland and H. W. Siesler, Appl. Spectrosc. Rev., 11, 1 (1976).

16. C. S. Paik Sung and C. B. Hu, J. Biomed. Mater. Res., 12, 791 (1978).

17. Van A. Prietzshk, Kolloid-Zeitshrift, 156, 8 (1958).

18. H. S. Suburamhanyan and J. S. Prasad, Mol. Cryst. Liq. Cryst., 37, 23 (1976).

19. R. M. Barrer and G. Skirrow, J. Polym. Sci., 3, 549 (1948).

20. R. M. Barrer, Trans. Faraday Soc., 35, 628 (1939).

21. J. Crank, "The Mathematics of Diffusion," Oxford Univ. Press, London, 1956.

22. H. Fujita, Fortschr. Hochpolym. Forsch., 3, 1 (1961).

23. A. Kishimoto, J. Polym. Sci., A, 2, 1421 (1964).

24. C. A. Boye, J. Polym. Sci., 55, 263 (1961).

25. G. Vergoten, Mol. Cryst. Liq. Cryst., 36, 327 (1976).

26. J. P. Sibilia, J. Appl. Polym. Sci., 17, 2911 (1973).

27. R. M. Barrer, "Diffusion in Polymers," J. Crank and G. S. Park, Eds., Academic Press, London and New York, 1968, p. 174.

28. H. P. Hopfenberg and H. L. Frisch, J. Polym. Sci., Polym. Lett. Ed., 7, 405 (1969). 